\title{
Sexual selection and mating system in Zorotypus gurneyi Choe (Insecta: Zoraptera)
}

\section{Dominance hierarchy and mating success}

\author{
Jae C. Choe ${ }^{1,2, *}$ \\ ${ }^{1}$ Department of Organismic \& Evolutionary Biology, The Biological Laboratories, Harvard University, Cambridge, MA 02138, USA \\ ${ }^{2}$ Smithsonian Tropical Research Institute, Balboa, Republic of Panama
}

Received: 12 February 1993/Accepted after revision: 2 November 1993

Summary. Social behavior of a species in the little-known insect order Zoraptera is described for the first time. Zorotypus gurneyi Choe (Insecta: Zoraptera) is a wing-dimorphic species that lives colonially under the bark of rotting logs in central Panama. Males are larger than females in total body size and fight each other to gain access to females. Highly linear and stable dominance hierarchies exist among males. Higher-ranking males show such agonistic behavior as jerking, chasing, headbutting, hindleg-kicking, and grappling, whereas subordinates often try to avoid contacts. Higher-ranking males, the dominant males in particular, are well recognized by others and relatively free of injuries. Although the dominant males are often the largest, the correlation between body size and dominance rank is not always significant. The mating system of $Z$. gurneyi is an example of female defense polygyny in which the dominant males obtain the majority of matings ( $75 \%$ on average). Mating success among Z. gurneyi males is much more variable than that of some lekking species.

Key words: Dominance - Female defense polygyny - Lek - Mating success - Zoraptera - Zorotypus gurneyi

\section{Introduction}

Sexual selection has two components: intrasexual and intersexual selection (Darwin 1871). Primarily because females invest more in offspring than males, males typically compete for females (intrasexual selection) and females exercise a choice of mates (intersexual selection) (Bateman 1948; Trivers 1972; Bateson 1983). Males adopt various mating strategies to influence female mate choice (Alcock 1979; Rubenstein 1980; Austad 1984). Dominance relations among males predetermine their mating success to a large extent in some group-living species

\footnotetext{
* Present address: Museum of Zoology, The University of Michi-
} gan, Ann Arbor, MI 48109-1079, USA such as elephant seals (LeBoeuf 1974), red deer (CluttonBrock et al. 1982), and yellow-rumped caciques (Robinson 1986). In olive baboons, however, male dominance rank is sometimes inversely correlated with consort success (DeVore 1965; Strum 1982).

Few insects have been studied with regard to the relationship between dominance hierarchy among males and their reproductive success (but see Breed et al. 1980; Crespi 1988). The zorapterans are colonial insects that live under the bark of rotting logs in tropical forests. Previously their biology was poorly understood, partly due to the difficulty of finding individuals in the field and maintaining healthy laboratory colonies. I developed a successful rearing technique which permits behavioral experiments on these little-known insects (Choe 1990, 1992). This paper provides the first information on the social behavior of the order Zoraptera and describes in detail (1) the social structure, (2) social behavior and dominance relationships among males, and (3) effects of social dominance on mating system and reproductive success in Zorotypus gurneyi from the lowland forests of central Panama.

\section{Methods}

Subjects. The zorapterans are minute, soft-bodied insects that occur throughout the tropical and subtropical regions. To date, there are only 30 described species, all of which belong to a single genus, Zorotypus, family, Zorotypidae, and order, Zoraptera. Zorotypus gurneyi is a recently described species from central Panama (Choe 1989). They are wing-dimorphic, although winged males are extremely rare. Wingless individuals are also eyeless and much more common than winged ones. More information on the biology of $Z$. gurneyi and the entire order can be found in Choe $(1990,1992)$.

Collecting. The study colonies of $Z$. gurneyi were collected from Parque Nacional Soberania, adjacent to the Panama Canal in central Panama, from November 1986 to March 1987. Decaying logs were located along a dirt road ("Pipeline Road") that starts from Gamboa and transverses the park. The bark was peeled off little by little and zorapterans were gently swept into a collecting jar by a fine brush. Every effort was made to ensure that the entire colony 
was recovered. Any incompletely collected colonies were not used in this study. Additional information on collecting zorapterans is provided in Choe (1992).

Identification of individuals. Individual zorapterans were identified by several natural features that vary among individuals, such as the number of antennal segments on each side, missing legs, and attachment pattern of mites. Although normal $Z$. gurneyi individuals have nine segments on each antenna, some are born with unequal numbers of antennal segments. Zorapterans also lose antennal segments from fighting. The combination of the two numbers, e.g., ' $8-9$ ' to indicate an individual with eight segments on the left antenna and nine on the right, was surprisingly effective in distinguishing individuals. Deutonymphs of an unidentified species of mite (Histiostoma sp. nov.; B. M. OConnor, personal communication) were found attached to various body parts of $Z$. gurneyi. A number of Histiostoma species are known to be phoretic on insects (OConnor 1993). Interestingly, the attachment sites of mites never changed during the experimental period and thus proved to be an effective additional identification mark. Only when these natural marks failed to provide adequate means of identification were individuals marked with a dot of white paint on one of the thoracic tergites. Only three males in colony VI were marked and no obvious abnormal behavior was noticed from these males.

Observation. Although colonies of various sizes were collected, colonies with fewer than six males were excluded from the study because a highly linear hierarchy among five or fewer individuals can be obtained by chance when the actual dominance relationships are random (Appleby 1983). Nonetheless, a few small colonies with fewer than six males were also observed, although the data from such colonies were not included in the quantitative analysis. General patterns in intermale interactions and mating system were similar to those from the study colonies. Colonies with ten or more males were also excluded, because it was increasingly difficult to record all behavioral interactions. The median number of males in all fieldcollected colonies $(n=39)$ was five.

Each colony was reared separately in the Smithsonian Tropical Research Institute laboratory on Barro Colorado Island in Panama. Plaster of paris was mixed with water and poured into a $14-\mathrm{cm}$ diameter petri dish. Once the plaster had hardened, the center (approximately $12 \mathrm{~cm}$ diameter, $0.5 \mathrm{~cm}$ deep) was carved out. The carved-out area or 'arena' was covered with red plastic to reduce disturbance from air turbulence and light. The zorapterans were kept in darkness with debris from their own natural habitat. They were fed yeast and crushed laboratory-rat chow, and humidity was maintained by sprinkling water on the uncarved portion of plaster along the rim of the petri dish. Observations were made under a dissecting microscope using a fiber-optic light source. Most individuals were eyeless and appeared to behave normally under cold light.

Observations began within 1 or 2 days after each colony was housed in the laboratory. Each colony was observed for $60 \mathrm{~h}(360 \mathrm{~h}$ for six colonies) during 5-7 consecutive days. In artificially constructed colonies, over $90 \%$ of all matings occurred within the first 4 days after the colonies were formed (Choe 1990). Observation sessions were arranged during both day and night to cover at least two full daily cycles for each colony. No marked difference was noted between the daily and nightly observations.

To determine dominance relationships among males, the following five types of behavioral interactions were recorded in terms of frequency, duration, win/loss, and injury:

- Contact avoidance. When two males are within one body-length of each other, they vibrate their antennae rhythmically and one walks away before touching the other.

- Chasing. One male runs after the other. It often follows other types of behavioral interaction such as head-butting or hindlegkicking.

- Head-butting. After a brief antennation, one male pushes the other with his head.
- Hindleg-kicking. Upon encountering another male, a male often turns around and immediately raises his hindquater. After a short pause, one male kicks the other with his hindlegs in much the same way that ungulates do. The male being kicked usually kicks back in response.

- Grappling. Two males grab each other and roll around together. It is the most escalated form of intermale aggression, through which males often lose such body parts as antennal segments and/or hindlegs.

After observation, all adults were killed in $75 \%$ alcohol, and their body lengths and hindfemur lengths were measured to the nearest $0.01 \mathrm{~mm}$ with an ocular micrometer. Voucher specimens have been deposited in the Museum of Comparative Zoology, Harvard University.

Analysis. Based on the outcomes of agonistic interactions among males, a dominance matrix was derived for each colony, using the method provided by Brown (1975). All six matrices were then combined to show mean scores. Males ranked below six were pooled and as a result there were six males in each of seven rank catergories.

The linearity of the dominance hierarchy among males in each colony was estimated using Landau's index of linearity $(h)$ (Landau 1951):

$h=12 /\left(N^{3}-N\right) \Sigma\left[S_{i}-(N-1) / 2\right]^{2}$

$N$ is the total number of males in a colony and $S_{i}$ is the number of individuals subordinate to $i$. The index value generally ranges from 0 (absence of linearity) to 1 (perfect linearity) and its statistical significance can be estimated using the method described by Appleby (1983).

The degree of mating skewness was determined by using the index, $H$, proposed by Bradbury et al. (1985):

$H=N /(N-1) \Sigma\left(C_{i}-1 / N\right)^{2}$

where $N$ is the number of males in a colony and $C_{i}$ is the proportion of matings attributed to the $i$ th male. The value of $H$ varies from 0 (perfectly even distribution of matings) to 1 (total monopoly by a single male).

Non-parametric tests were used whenever the assumptions of normality were not met. All tests are two-tailed and data are presented as mean $\pm 1 \mathrm{SD}$.

\section{Results}

\section{Colony composition}

In the six study colonies females were generally more abundant $(\bar{x} \pm \mathrm{SD}=10.5 \pm 4.1)$ than males $(7.0 \pm 1.3)$ (Table 1). Each colony had, on average, $12.8 \pm 1.9$ nymphs at various developmental stages (Table 1). Four nymphs emerged as adults ( 3 males and 1 female) during the observation period and they are treated as adults in Table 1 . Winged individuals were extremely rare. All five winged adults were female. The average colony size was $30.3 \pm 5.4$

\section{Size distribution}

Males have longer hindfemora $(0.79 \pm 0.03 \mathrm{~mm}, n=42)$ than females do $(0.73 \pm 0.02 \mathrm{~mm}, n=63$; Mann-Whitney $U$-test, $Z=7.318, P<0.001$ ) (Fig. 1). There are 9-11 
Table 1. Composition of six Zorotypus gurneyi colonies used in the study

\begin{tabular}{llccc}
\hline Colony & Adult male & Adult female & Nymph & Total \\
\hline I & 6 & 8 & 13 & 27 \\
II & 6 & 4 & 11 & 21 \\
III & 6 & 15 & 11 & 32 \\
IV & 7 & 10 & 16 & 33 \\
V & 8 & 14 & 14 & 36 \\
VI & 9 & 12 & 12 & 33 \\
\hline
\end{tabular}
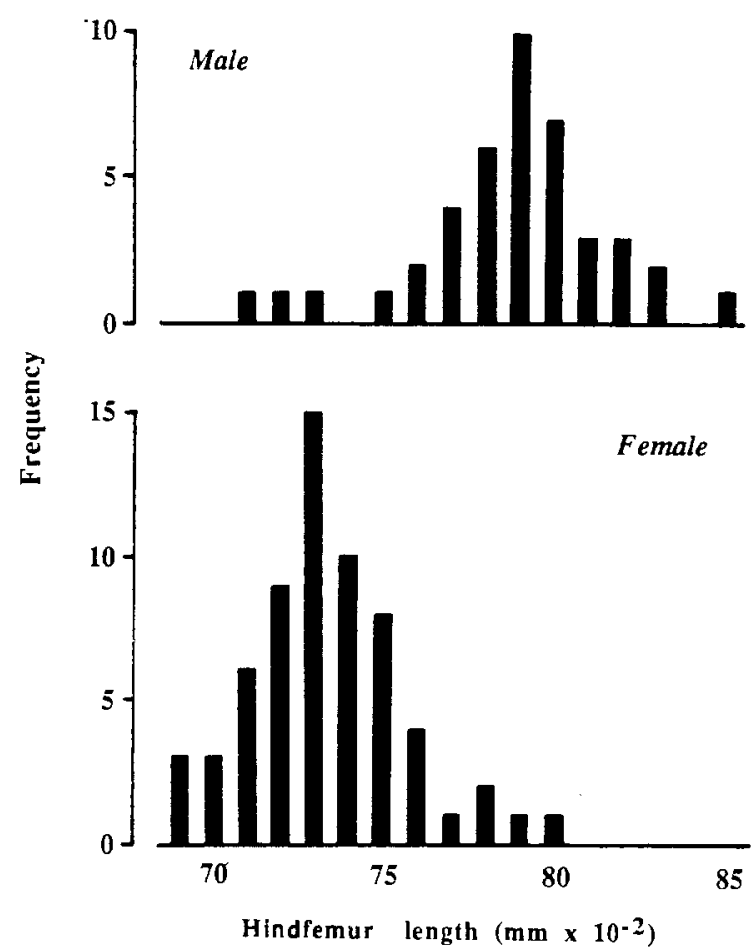

Fig. 1. Size (hindfemur length) distributions for males $(n=42)$ and females ( $n=63$ ) of Zorotypus gurneyi in six study colonies

thick spines on the posterior margin of each hindfemur in both sexes. Females have smaller spines as they have smaller hindfemora. There was a significant positive correlation between the total body length and hindfemur length $(r=0.866, P<0.001, n=105)$, indicating that hindfemur length is a good indicator of body size.
Agonistic interactions and dominance hierarchy

As mentioned above, $Z$. gurneyi live in darkness under the bark of rotting logs, and most individuals are wingless and eyeless. Antennation appears to be the major mode of communication. After a single stroke of antennation, individuals appear able to assess one another with respect to relative dominance and sex.

A total of 16,252 male-male interactions were recorded from six study colonies. The most common interaction was contact avoidance $(43.8 \% ; 7112)$, closely followed by head-butting $(40.8 \%$; 6634). Males chased others 2431 times $(15.0 \%)$ and each chase usually took less than a second. Nearly half $(48.6 \%)$ of all recorded chases were done by the dominant males. In fact, chasing was the most common $(67.7 \%)$ behavior of the dominant males. Although males were engaged in a rear-to-rear hindlegraising display 184 times, they kicked with the hindlegs only 72 times $(0.4 \%)$. Only three grapple fights were observed and they lasted for less than $1 \mathrm{~s}$. Grappling zorapterans grabbed each other's body parts in much the same way that professional wrestlers perform arm-locks; hindfemoral spines were used to pin down and pull the opponent's antenna, leg, or even head.

I considered the male that walked away or fled in any of the four types of behavioral interaction the loser and the compiled dominance matrix is given in Table 2. From these win/loss data emerged two categories of males: higher-ranking males, i.e., the first, second, and thirdranking males whose win/loss ratios were $80 \%$ or higher, and lower-ranking males whose win/loss ratios were $20 \%$ or lower. The dominant males had fewer interactions than the second-ranking males in all six colonies $\left(\chi^{2}=17.71, P<0.01\right)$, because most subordinates stayed away from the dominant males.

Hierarchies of five out of six colonies had linearity indices greater than 0.9 (Table 3), which is considered highly linear (Chase 1974; Bekoff 1977) and all were significant $(P<0.01)$, indicating that dominance relationships were not generated randomly in all six colonies. Another commonly used measure of linearity, Kendall's coefficient (Appleby 1983), was also estimated and the values were virtually identical to those of Landau's index. In only 933 interactions (5.7\%) did a higher-ranking male lose to a lower-ranking male (Table 2), indicating that dominance relationships among males were clear in most cases.

Table 2. Outcome of agonistic interactions among Zorotypus gurneyi males

\begin{tabular}{|c|c|c|c|c|c|c|c|c|}
\hline Rank & 1 & 2 & 3 & 4 & 5 & 6 & $>6$ & Wins \\
\hline 1 & - & $234 \pm 86$ & $214 \pm 92$ & $176 \pm 53$ & $99 \pm 22$ & $60 \pm 10$ & $38 \pm 5$ & $801 \pm 235$ \\
\hline 2 & 0 & - & $356 \pm 94$ & $301 \pm 79$ & $228 \pm 28$ & $110 \pm 17$ & $91 \pm 5$ & $1040 \pm 244$ \\
\hline 4 & 0 & $1 \pm 1$ & $15 \pm 5$ & - & $81 \pm 13$ & $44 \pm 15$ & $39 \pm 9$ & $159 \pm 31$ \\
\hline 5 & 0 & 0 & $9 \pm 3$ & $53 \pm 15$ & - & $41 \pm 14$ & $31 \pm 8$ & $119 \pm 19$ \\
\hline 6 & 0 & 0 & 0 & $22 \pm 11$ & $31 \pm 11$ & - & $30 \pm 11$ & $68 \pm 28$ \\
\hline
\end{tabular}

Each figure is mean $\pm \mathrm{SD}$ estimated from six study colonies 
Table 3. Landau's index $(h)$ of linearity of dominance hierarchies and values of Spearman's correlation $\left(r_{\mathrm{s}}\right)$ between hindfemur length and dominance rank among Zorotypus gurneyi males in six study colonies

\begin{tabular}{lllll}
\hline Colony & $h$ & Significance & $r_{\mathrm{s}}$ & Significance \\
\hline I & 1.000 & $P<0.01$ & 0.943 & $P<0.05$ \\
II & 1.000 & $P<0.01$ & 1.000 & $P<0.005$ \\
III & 1.000 & $P<0.01$ & 0.405 & ns \\
IV & 1.000 & $P<0.01$ & 0.893 & $P<0.05$ \\
V & 0.833 & $P<0.01$ & 0.405 & ns \\
VI & 0.967 & $P<0.01$ & 0.683 & ns \\
\hline
\end{tabular}

Table 4. Frequency of injuries among Zorotypus gurneyi males in each dominance rank

\begin{tabular}{|c|c|c|c|c|c|c|c|}
\hline & \multicolumn{7}{|c|}{ Dominance rank } \\
\hline & \multicolumn{3}{|c|}{ Higher-ranks } & \multicolumn{4}{|c|}{ Lower-ranks } \\
\hline & 1 & 2 & 3 & 4 & 5 & 6 & $>6$ \\
\hline $\begin{array}{l}\text { Missing antennal } \\
\text { segments }\end{array}$ & 1 & 2 & 3 & 3 & 5 & 2 & 4 \\
\hline Missing a hindleg & 0 & 0 & 1 & 2 & 3 & 2 & 2 \\
\hline
\end{tabular}

The dominant male behaved in an obvious way. $\mathrm{He}$ walked slowly in the center of the arena, often vibrating his antennae vigorously in a rhythmic fashion, whereas subordinates walked swiftly along the edge of the arena (Fig. 2). Only the second, the third, and occasionally the fourth highest males sometimes ventured near the dominant male. The dominant male also showed frequent jerking movements, most of which were not necessarily aimed at any particular individual. The duration of a jerking bout lasted for $4.2 \pm 6.6 \mathrm{~s}(n=40)$. All three cases of grapple fights were initiated by the dominant males.

The dominant male was also the largest in four colonies; in the other two the second and third largest male, respectively, were dominant. In general, there was a trend for higher-ranking males to be larger, but dominance rank and hindfemur length were not significantly correlated $(P>0.05)$ in three out of six colonies (Table 3$)$. Higher-ranking males generally had darker exoskeletons than lower-ranking males, suggesting that age might be an important determinant of dominance.

Among the most noticeable injuries were losses of antennal segments and a hindleg. Frequency of missing antennal segments did not significantly differ between higher-ranking and lower-ranking males $\left(\chi^{2}=1.35\right.$, $P>0.05$ ), while missing a hindleg was much more frequent among lower-ranking males than higher-ranking ones $\left(\chi^{2}=4.41, P<0.05\right.$; Table 4$)$. Individuals were missing up to six segments in either antenna, but none were missing both hindlegs. Although few injuries were witnessed at the point of infliction, I observed two subordinate males lose five antennal segments and a hindleg, respectively, during grapple fights with the dominant males.

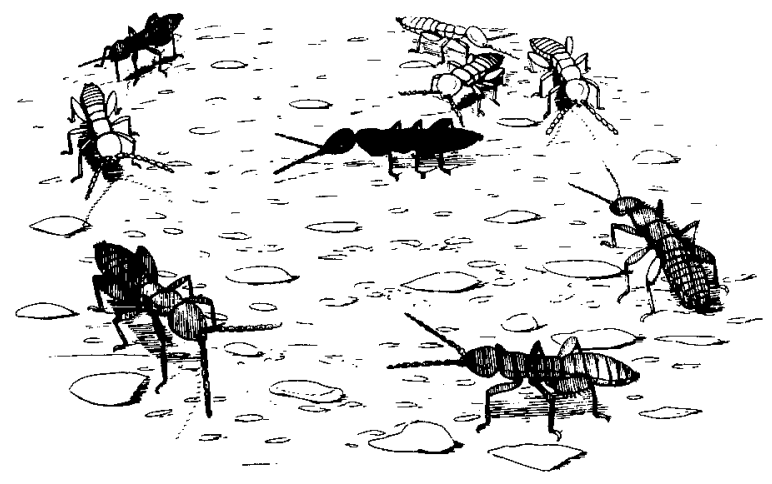

Fig. 2. A typical scene in a $Z$. gurneyi colony, showing the dominant male (black) in the center, subordinate males (shaded), and females (white)

\section{Behavior of females}

Females were constantly pursued by males. They also showed hindleg raising and kicking behavior toward males and sometimes females. Females tended to form a loose but definite clump and the dominant male appeared to defend the harem by constantly chasing subordinates away from it (Fig. 2).

\section{Behavior of nymphs}

Nymphs' behavior was essentially unaffected by the dominance hierarchy. Most spent much of their time hiding in crevices. However, when they move about, they ran into and disturbed any member of the colony. Adults of either sex appeared to provide parental care for nymphs. No care or cannibalism was observed of eggs.

\section{Dominance and mating success}

The dominant males constantly chased and attempted to copulate with females. Precopulatory behavior was rather simple and brief. Following a brief antennation and jerking by the male, some females turned around and took a few steps backward toward the male. The male then almost instantaneously turned around and copulated with the female, turning upside down as he did so (Fig. 3). Copulations lasted for $55.6 \pm 4.9 \mathrm{~min}(n=76)$. The durations of copulation by the dominant and subordinate males did not differ $(P>0.05$; Mann-Whitney $U$ test). Copulating pairs were often attacked by others, most of whom were female $(86.2 \%)$. The copulating female either fought back or ran away dragging the male around. It appeared that the male terminated a copulation by releasing the female.

Of 76 copulations, $55(72.4 \%)$ were performed by the dominant males (Fig. 4). On average the dominant male copulated $9.2 \pm 2.9$ times $(74.5 \pm 10.8 \% ; n=6$ colonies), whereas subordinate males obtained only occasional copulations. The mean value of $H$ (index of mating skew) for the six colonies was $0.510 \pm 0.143$ (range: 0.286 0.580 ). 


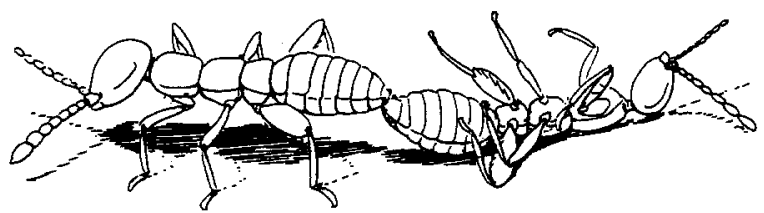

Fig. 3. Mating posture of $Z$. gurneyi: the female maintains a forward upright position, while the male is upside down

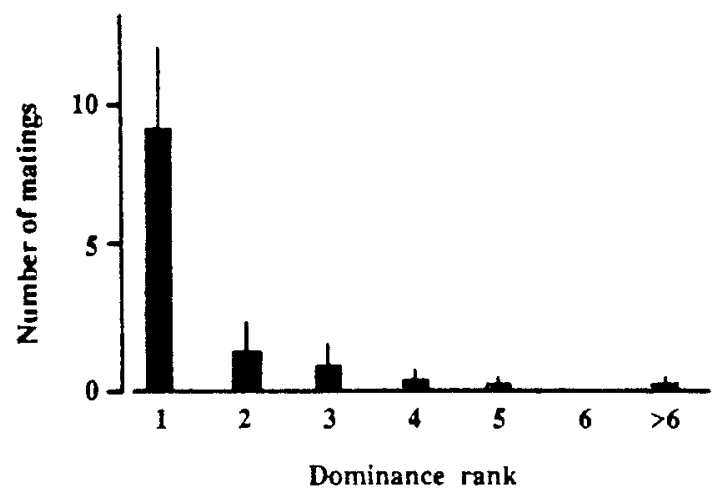

Fig. 4. Number of matings (mean $\pm S D$ ) obtained by males of different dominance ranks in six study colonies. Each rank category has six males

A total of 48 females (76.2\%) mated only once during the observation period. Eight females $(12.7 \%)$ mated twice, while four $(6.3 \%)$ mated three times. Of the 12 females who mated more than once 5 mated with more than one male. Three females $(4.8 \%)$ were never seen mating.

\section{Field observation}

Field observations were made by replacing the bark with a red plastic sheet. Although detailed behavior of individuals could not be monitored, the general appearance of movements in the field colonies resembled that seen in the laboratory colonies. Occasionally, I encountered large colonies with up to several hundreds of individuals in the field. I could not determine whether a single most dominant male monopolized the access to most females or several males held harems of various sizes in such a large colony.

\section{Discussion}

\section{Mating system}

The mating system of $Z$. gurneyi may represent a form of female defense polygyny. Dominant males did not appear to defend resources or oviposition sites used by females. Instead, they directly pursued females. Females tended to form a loose but definite clump or harem. Dominant males appeared to actively prevent other males from gaining access to females in much the same way that stags do (Clutton-Brock et al. 1982).
The direct monopolization of a harem of females is rare in insects (Thornhill and Alcock 1983). Most insects are highly mobile and do not live in a closed social unit. In those cases where harem defense occurs, females usually emerge in clusters (see Thornhill and Alcock 1983 for examples). In $Z$. gurneyi, however, adult females emerge throughout the year, but live in more or less confined spaces. Insects that live in a closed microhabitat, such as the space under the bark, and/or have reduced flight abilities would be good candidates for the direct monopolization of females by males.

\section{Intermale conflicts and dominance hierarchy}

Since early study of social dominance in domestic chickens (Schjelderup-Ebbe 1922), dominance hierarchies have been thought to be highly linear in most species. According to an analysis by Jackson and Winnegrad (1988), however, only $26(41.9 \%)$ out of 62 hierarchies reported in the literature were strongly linear.

Zorotypus gurneyi males establish and maintain highly linear dominance hierarchies. In this study, only colony $\mathrm{V}$ had a linearity index value below 0.9 . The value of Spearman's correlation between body size and dominance rank for colony $\mathrm{V}$ was also insignificant, and the lowest among six colonies. In that colony the largest and second largest males were ranked sixth and fifth, respectively, and had injuries; possibly they were aging and descending the hierarchy. This transient situation may have been responsible for the lowest degree of mating skew recorded from this colony.

Dominance hierarchies among $Z$. gurneyi males were also stable as well as linear. None of the dominant males was displaced by other males during the observation period, although they were sometimes challenged by immediate subordinates. Dominance ranks were well recognized, especially for the top three males, as indicated by the order of magnitude differences between wins and losses. The exact mechanism of rank or individual recognition is unclear, but contact avoidance behavior among males suggests that some sort of short-range chemical signal may be involved in the communication system of $Z$. gurneyi. A brief antennation between individuals, often consisting of a single stroke, is perhaps a way of verifying chemically-transmitted information.

Because the study colonies were collected more or less intact in the field where the dominance hierarchies had already been established, it was not possible to witness how the hierarchies develop in $Z$. gurneyi. Rare glimpses were provided when three nymphs emerged as adult males during the observation period. The dominant males were always the first to approach and make a series of attacks toward newly emerged males. These newly emerged males tended to venture toward the center of the arena more often than other subordinate males, possibly provoking the dominant males, but the dominant males also appeared to actively seek out and chase the new males. Many of the males at the bottom of the hierarchies had a pale exoskeleton, indicating that they were young males. Adults emerge throughout the year and it appears 
that newly emerged males must start from the bottom of the hierarchy (Choe 1994).

Lower-ranking males were missing a hindleg much more frequently than higher-ranking ones, while frequency of missing antennal segments did not differ significantly between the two categories of males. Although antennation appears to be an integral part of communication among zorapterans, losing some antennal segments may not greatly affect their dominance dynamics. It is not always clear whether the relation between dominance and injury level is causal, but on two occasions I observed males descending the hierarchy after the loss of a hindleg during grapple fights (Choe 1994). The current dominant males may simply be those that have managed to avoid serious injuries in the past. Dominant males showed nearly continuous jerking and chasing movements. Such behavior may be energetically costly, but can reduce the risk of being injured in actual fights. Body size seems to be an important variable in determining the dominance hierarchy among $Z$. gurneyi males, but is generally overriden by the effects of age, or more specifically, the male's tenure i.e., length of time the male has been in the colony (Choe 1994).

\section{Mating success and sexual selection}

Dominant males had disproportionately more access to females and thus obtained the majority of matings in $Z$. gurneyi. On the other hand, nearly all females were seen to mate at least once in 5-7 days of observation. Thus, the intensity of sexual selection is greater on males than on females in $Z$. gurneyi. In this study, reproductive success is measured as mating success, which is obviously the compound result of several selective episodes (Howard 1978; Arnold and Wade 1984). The variance in male reproductive success depends on two factors: the variance due to differences in fecundity among females and the variance in the number of females with which a male mates (Wade and Arnold 1980). It was not possible to monitor how many eggs each female $Z$. gurneyi laid, because there was no prefered oviposition site for any particular female. Although multiple mating by females was only moderate in $Z$. gurneyi, there still is a potential for sperm competition because some females mate with more than one male.

Male mating success is most variable in polygynous species (Wilson 1975; Emlen and Oring 1977), and is thought to be most skewed in lekking species (e.g., Payne 1984). Contrary to this prediction, the $H$ values for the six study colonies of $Z$. gurneyi were considerably higher $(0.510 \pm 0.143$; range: $0.286-0.667 ; n=6)$ than the values for 11 studies of five lekking species $(0.337 \pm 0.113$; range: $0.154-0.515 ; n=11$ ) in Bradbury et al. (1985). The linearity and stability of the dominance hierarchy in Z. gurneyi may enhance the degree of mating skew. A more fundamental problem exists, however, as to which males ought to be included in the analysis. To accurately assess the actual mating distribution in polygynous species, all mature males in the population, reproductively successful or not, should be included. Most studies of polygy- nous species do not provide accurate information on how many males are present without territories or harems (Searcy and Yasukawa 1983). Exclusion of such males can reduce the degree of mating skew, and without such information, it is difficult to test if mating success is indeed more variable in lekking species than other polygynous species.

Acknowledgements. I benefited tremendously from discussions with William Eberhard and Mary Jane West-Eberhard. Peter Adler, Richard Alexander, Steven Austad, Russell Burke, William Eberhard, Brian Hazlett, Bert Hölldobler, Wendy Jackson, Charles Michener, Bruce Waldman, Edward Wilson, and two anonymous reviewers made valuable comments on various drafts. My wife, H.K., has been a loving and understanding companion both in the field and home. I thank Barry OConnor for identifying mites. Kathy Brown-Wing made line drawings of zorapterans. The Smithsonian Tropical Research Institute and the Panamanian park service (RENARE) made my research in Panama possible. The Michigan Society of Fellows provided me with an ideal intellectual haven during the writing phase. I gratefully acknowledge financial support from the Predoctoral Fellowship of the Smitbsonian Institution, Theodore Roosevelt Memorial Fellowship, Sigma Xi Grants-inAid, Richmond fund, deCuevas Fund, and Graduate Fellowship of Harvard University.

\section{References}

Alcock J (1979) The evolution of intraspecific diversity in male reproductive strategies in some bees and wasps. In: Blum MS, Blum NA (eds) Sexual selection and reproductive competition in insects. Academic Press, New York, pp 381-402

Appleby MC (1983) The probability of linearity in hierarchies. Anim Behav 31:600-608

Arnold SJ, Wade MJ (1984) On the measurement of natural and sexual selection: theory. Evolution 38:709-719

Austad SN (1984) A classification of alternative reproductive behaviors and methods for field-testing ESS models. Am Zool $24: 309-319$

Bateman AJ (1948) Intra-sexual selection in Drosophila. Heredity 2:349-368

Bateson P (1983) Mate choice. Cambridge University Press, Cambridge

Bekoff M (1977) Quantitative studies of three areas of classical ethology: social dominance, behavioral taxonomy, and behavioral variability. In: Hazlett BA (ed) Quantitative methods in the study of animal behavior. Academic Press, New York, pp 1-46

Bradbury JW, Vehrencamp SL, Gibson R (1985) Leks and the unanimity of female choice. In: Greenwood PJ, Harvey PH, Slatkin $M$ (eds) Evolution. Cambridge University Press, Cambridge, pp 301-314

Breed MD, Smith SK, Gall BG (1980) Systems of mate selection in a cockroach species with male dominance hierarchies. Anim Behav 28:130-134

Brown JL (1975) The evolution of behavior. Norton, New York

Chase ID (1974) Models of hierarchy formation in animal societies. Behav Sci 19:374-382

Choe JC (1989) A new species Zorotypus gurneyi from Panama and redescription of $Z$. barberi Gurney (Zoraptera: Zorotypidae). Ann Entomol Soc Am 82:149-155

Choe JC (1990) The evolutionary biology of Zoraptera (Insecta). $\mathrm{PhD}$ dissertation, Harvard University, Cambridge

Choe JC (1992) Zoraptera of Panama with a review of the morphology, systematics, and biology of the order. In: Quintero D, Aiello A (eds) Insects of Panama and Mesoamerica: selected studies. Oxford University Press, Oxford, pp 249-256 
Choe JC (1994) Sexual selection and mating system in Zorotypus gurneyi Choe (Insecta: Zoraptera): II. Determinants and dynamics of dominance. Behav Ecol Sociobiol

Clutton-Brock TH, Guinness FE, Albon SD (1982) Red deer: behavior and ecology of two sexes. University of Chicago Press, Chicago

Crespi BJ (1988) Risks and benefits of lethal male fighting in the colonial, polygynous thrips Hoplothrips karnyi (Insecta: Thysanoptera). Behav Ecol Sociobiol 22:293-301

Darwin C (1871) The descent of man and selection in relation to sex. John Murray, London

DeVore I (1965) Male dominance and mating behavior in baboons. In: Beach F (ed) Sex and behavior. Wiley, New York, pp $266-$ 289

Emlen ST, Oring LW (1977) Ecology, sexual selection, and the evolution of mating systems. Science 197:215-223

Howard RD (1978) The evolution of mating strategies in bullfrogs, Rana catesbeiana. Evolution 32:850-872

Jackson WM, Winnegrad RL (1988) Linearity in dominance hierarchies: a second look at the individual attributes model. Anim Behav 36:1237-1240

Landau HG (1951) On dominance relations and the structure of animal societies. I: Effect of inherent characteristics. Bull Math Biophys 13:1-19

LeBoeuf BJ (1974) Male-male competition and reproductive success in elephant seals. Am Zool 14:163-176
OConnor BM (1993) Life-history modifications in astigmatid mites. In: Houck MA (ed) Mites: ecological and evolutionary analyses of life-history patterns. Chapman-Hall, New York, pp 136-159

Payne RB (1984) Sexual selection, lek and arena behavior, and sexual size dimorphism in birds. Ornithol Monogr 33:1-52

Robinson SK (1986) Benefits, costs, and determinants of dominance in polygynous oriole. Anim Behav 34:241-155

Rubenstein DI (1980) On the evolution of alternative mating strategies. In: Staddon JER (ed) Limits to action: the allocation of individual behavior. Academic Press, New York, pp 65-100

Schjelderup-Ebbe T (1922) Beitrage zur Sozialpsychologie des Haushuhns. Z Psychol 88:225-252

Searcy WA, Yasukawa K (1983) Sexual selection and red-winged blackbirds. Am Sci 71:166-174

Strum SC (1982) Agonistic dominance in male baboons: an alternative view. Int J Primatol 3:175-202

Thornhill R, Alcock J (1983) The evolution of insect mating systems. Harvard University Press, Cambridge

Trivers RL (1972) Parental investment and sexual selection. In: Campbell BG (ed) Sexual selection and the descent of man. Aldine, Chicago, pp 136-179

Wade MJ, Arnold SJ (1980) The intensity of sexual selection in relation to male sexual behavior, female choice, and sperm precedence. Anim Behav 28:446 461

Wilson EO (1975) Sociobiology: the new synthesis. Harvard University Press, Cambridge 